and 'psychotherapy'. Personal tragedies were also blamed for difficulties in maintaining interest in one's work by a significant minority. Several coping strategies were reported as being helpful, especially: 'turning off after work, maintaining outside interests, research, and 'devaluation' of perceived opponents. Most respondents felt that the questionnaire was not detailed enough to tap the essence of burnout. Two respondents questioned its validity as an entity. In contrast to Morrice, we were struck by the openness and honesty of the respondents, many of whom signed their questionnaires. We are indeed grateful to them.

In conclusion, whilst we do not feel that Dr Morrice's questionnaire measured a specific syndrome, we do believe that we tapped, if not lanced, a boil.

BrIAN O'SHEA AIDAN MCGennis Michele CAHIIL

St Brendan's Hospital

Dublin

DeAR Sirs

\section{'Clomipramine Challenge Test'}

I should like to take up Dr Holmshaw's invitation to comment on his 'Clomipramine Challenge Test' (Bulletin, April 1984, 8, 76).

I am extremely concerned that Dr Holmshaw should feel it is appropriate for a psychiatrist deliberately to induce 'florid schizophrenic psychosis' in susceptible people by neuropharmacological methods.

In addition, I wonder whether I might assume that $\mathrm{Dr}$ Holmshaw follows usual medical practice by informing his patients of the desired effects of the drugs he gives them, and also of any likely side-effects.

The Tavistock Clinic

D. V. CARPY

120 Belsize Lane, London NW3

\section{Self-damage in patients with Klinefelter's Syndrome}

DeAr Strs

Two of us (Prof R. G. Priest and Dr G. G. Wallis) found out by chance that we had a patient each who both showed striking features in common. They both have been diagnosed as Klinefelter's syndrome and XXY constitution has been confirmed on chromosomal assay. They are both persistent self-mutilators of an extreme degree, and show extensive scarring from skin cuts. Both have been diagnosed as having gross personality disorder. They are single, with scanty facial hair and atrophic testes. One is 25 years old and the other is 33.

There are also differences. The younger one has diffuse slow waves in the EEG, and the older one has had psychotic features. The younger one is quite intelligent, and the older one has an intelligence in the dull-normal range intelligence. Both have taken overdoses, but the younger has swallowed razor blades, and abused alcohol and other drugs.

Although self-cutting is well known to occur in patients of definitely subnormal intelligence, it is not so common in adults in the normal intellectual range. In the patients described here it seems to be more related to their abnormal personalities. ${ }^{1,2}$

We are wondering if other psychiatrists have encountered this combination of Klinefelter's syndrome and persistent self-mutilation. If so, through the courtesy of your columns we should like to invite them to write to us so that we may build up a picture of the resulting syndrome, if such an entity exists.
Rainhill Hospital
D. A. AdDala
Prescot, Merseyside

St Mary's Hospital $\quad$ R. G. PRIEST

London $\mathbf{W} 2$

Fulford Grange Hospital G. G. WALLIS

Rawdon, Leeds

\section{REFERENCES}

'Priest, R. G. (1979) Aggression and suicide. In Aetiology and Management of Affective Disorders (ed. A. M. Jukes). Horsham: Ciba.

2_ \& Woolpson, G. (1978) Minski's Handbook of Psychiatry. London: Heinemann.

\section{$A$ 'College recommended' textbook of psychiatry?}

\section{DeAR SIRS}

During our preparations for the second part of the examination for membership of the College, my friends and I noted the large number of books we had to refer to, in order to gather what information we felt would meet the requirements of the examination. Even then, depending on our sources, we held different views on important issues.

I suggest that the College considers appointing a special Task Force to produce a Standard Textbook of Psychiatry, in two volumes. Volume I would cover the theoretical requirements for the MRCPsych Preliminary Test, and Volume II would do the same for the Membership Examination.

The general idea is that the two volumes of the Standard Textbook of Psychiatry would represent views generally agreed by the College on the essential theoretical material of psychological medicine. As such, they will serve not only to facilitate the training of psychiatrists, but also (much more importantly) help to bring into coordination what the College sees as psychiatry.

\section{Royal Free Hospital}

IKECHUKWU AZUONYE

Hampstead, London NW3 